Recepción: 27 / 02 / 2018

Aceptación: 01 / 05 / 2018

Artículo Científico

Publicación: 05 / 06 / 2018

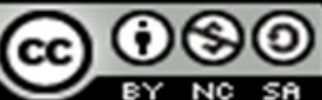

Ciencias de la Educación

\title{
Una mirada acerca de la comunicación en la Educación Superior
}

\section{A look about communication in Higher Education}

Maria L. Parrales-Poveda ${ }^{\mathrm{I}}$

marialparrales@hotmail.com

Jipijapa; Ecuador

Diego R. Sornoza-Parrales II

Diegosornoza@hotmail.com

Jipijapa; Ecuador

Rocio J. Cano-Andrade ${ }^{\text {III }}$

rociocanoandrade@hotmail.com

Jipijapa; Ecuador

Mercy K. Moreira-Cañarte ${ }^{\text {IV }}$

Mercymoreirac@hotmail.com

Jipijapa; Ecuador

Correspondencia: marialeonor_72@hotmail.com

I. Universidad Estadal del Sur de Manabí; Jipijapa, Ecuador.

II. Universidad Estadal del Sur de Manabí; Jipijapa, Ecuador

III. Universidad Estadal del Sur de Manabí, Jipijapa, Ecuador.

IV. Universidad Estadal del Sur de Manabí, Jipijapa, Ecuador. 
Maria L. Parrales-Poveda; Diego R. Sornoza-Parrales; Rocio J. Cano-Andrade; Mercy K. Moreira-Cañarte

\title{
Resumen
}

Se realizo una revisión bibliografía acerca de la comunicación en la educación superior en el cual se exponen definiciones de la comunicación, elementos de la misma, componentes sociopsicologicos, asimismo la comunicación en el proceso educativo y resultados de investigaciones acerca del uso de las TIC.

Palabras claves: Educación, educación superior, comunicación, TIC.

\begin{abstract}
A bibliography review was made about communication in higher education in which definitions of communication, elements of it, socio-psychological components, as well as communication in the educational process and research results about the use of ICT are exposed.
\end{abstract}

Keywords: Education, higher education, communication, ICT. 


\section{Introducción.}

La sociedad debe apropiarse de valores que expresen tradiciones e ideales, de proyectos realizables del cual exista un reconocimiento y respeto mutuo la équida, solidaridad y la paz. La educación tiene la responsabilidad de preparar al individuo y la sociedad de todo el universo necesario para vivir a tono al desarrollo de todas sus posibilidades físicas y espirituales. Esto da razón que de ser a la educación como un práctica enculturizadora. ${ }^{1}$

La Universidad que constituye el modelo clásico de organización de educación superior, se distingue por tres funciones básicas: enseñanza, investigación y extensión. En este modelo los conocimientos se generan mediante la investigación, son transferidos a individuos que los necesitan mediante la docencia y aplicados a la sociedad por sus egresados o por los profesores a través de proyectos o servicios de asesoría hacia la comunidad.

La diversidad del sistema de educación superior es mayor que cualquiera de los otros sistemas que conforman el sistema educativo de un país. Podemos tener instituciones que son unifuncionales que ejercen fundamentalmente la docencia y otras multifuncionales que realizan las funciones de docencia, investigación y extensión. Hay universidades que se dedican por ejemplo a las áreas técnicas solamente como las ingenierías y arquitectura o a las humanidades mientras que otras cumplen más a todos los campos. Las hay públicas y privadas de acuerdo al financiamiento. ${ }^{2}$

La preparación que brinda la educación superior es de tipo profesional o académica. Se distingue entre estudios de pregrado, grado (carrera universitaria) y posgrado (Máster y Doctorado) según el sistema de titulación profesional y grados académicos. 
Los establecimientos de educación superior han sido tradicionalmente las universidades, pero además se consideran otros centros educacionales como institutos, escuelas profesionales o escuelas técnicas, centros de formación del profesorado, escuelas o institutos politécnicos, etc. (las denominaciones dependen del sistema educacional del país en particular).

Una función importante, aparte de la enseñanza, en la educación superior son las actividades de investigación en los distintos niveles del saber. Otra importante función es la que corresponde a actividades de extensión, en las que se procura la participación de la población y se vuelca hacia ella los resultados.

Con base en lo anterior se puede afirmar que la educación superior y de cualquier otra índole debe trascender a la sociedad. La educación superior que no se involucre socialmente deja mucho que desear, debido a que lo ideal de la educación es que la persona que la reciba comprenda que es un ser social y que debe servirle no solo a él o ella, sino también a la sociedad a la cual pertenezca o dentro de la cual interactué. ${ }^{3}$

\section{Definición de comunicación.}

La palabra comunicación proviene del latín communis, que significa común por lo que comunicarse quiere decir establecer comunidad con alguien. La comunicación es un proceso realizado en casi todos los aspectos de la vida humana. Desde los albores de la humanidad, el hombre buscaba la forma de comunicarse a través de los distintos medios que iban desde los gestos, la voz, los caracoles, los tambores, señales de humo, etc. En la medida que se produce el desarrollo de la civilización fueron evolucionando las formas y los sistemas de comunicación. 
Existen muchas definiciones sobre qué se entiende por comunicación. Estos conceptos dependen fundamentalmente de la concepción filosófica, metodológica y teórica del autor. ${ }^{4}$

Se plantea que la comunicación, es el proceso de transmisión y recepción de ideas, información y mensajes. El acto de comunicar es un proceso complejo en el que dos o más personas se relacionan $\mathrm{y}$, a través de un intercambio de mensajes con códigos similares, tratan de comprenderse e influirse de forma que sus objetivos sean aceptados en la forma prevista, utilizando un canal que actúa de soporte en la transmisión de la información. Es más un hecho sociocultural que un proceso mecánico.

La comunicación ha sido teorizada, subvalorada, redimida y manejada de tantas formas que a veces se obvia su importancia por la cotidianidad con que es vista. Sin embargo es tan antigua como las primeras civilizaciones, que mientras más se complejizaban más crecía su necesidad de desarrollarse y por tanto de interactuar entre ellos. Con la diferenciación de roles, la división del trabajo y el establecimiento de jerarquías en busca de beneficios comunes, el nivel de organización creció y se hizo imprescindible la evolución del lenguaje.

Con los años, la comunicación dejó de ser únicamente lenguaje, para convertirse paulatinamente en medio de comunicación masiva y mediación cultural. En los tiempos modernos comunicar significa poner en común con otro, ideas, pensamientos, a través de diferentes canales y con un código compartido. Debido a esto resulta un fenómeno difícil de conceptualizar; existen disímiles definiciones, ha sido estudiada y tratada con diferentes enfoques. ${ }^{5}$

Respecto a los tipos de comunicación, podemos señalar la comunicación verbal y la no verbal. Teniendo como elementos fundamentales: 
- El mensaje. Formado por las diferentes ideas o informaciones, que se transmiten mediante códigos, claves, imágenes, etc., cuyo significado interpretará el receptor.

- El emisor y el receptor. El emisor es el sujeto que comunica en primer lugar o toma la iniciativa de ese acto de comunicación, mientras que el receptor es el que recibe el mensaje.

- El código. Es el conjunto de claves, imágenes, lenguaje, etc., que sirven para trasmitir el mensaje. Debe de ser compartido por emisor y receptor.

- El canal. Es el medio a través del cual se emite el mensaje. Habitualmente se utiliza el oralauditivo y el gráfico-visual complementándose.

- El contexto. Se refiere a la situación concreta donde se desarrolla la comunicación. De él dependerá en gran parte la forma de ejercer los roles por parte de emisor y receptor.

- Los ruidos. Son todas las alteraciones de origen físico que se producen durante la transmisión del mensaje.

- Los filtros. Son las barreras mentales, que surgen de los valores, experiencias, conocimientos, expectativas, prejuicios, etc. de emisor y receptor.

- El feedback o la retroalimentación. Es la información que devuelve el receptor al emisor sobre su propia comunicación, tanto en lo que se refiere a su contenido como a la interpretación del mismo o sus consecuencias en el comportamiento de los interlocutores. ${ }^{5}$

\section{Los componentes sociopsicológicos de la comunicación.}

La información, la interacción y la percepción constituyen los componentes sociopsicológicos de la comunicación y se revelan en los procesos comunicativos a partir de los pequeños grupos. 
- Componente comunicativo: aprecia la comunicación como intercambio de información.

Cada miembro del proceso debe ser considerado un ente activo, no como un objeto sino como sujeto. La influencia comunicativa se logra si en la relación emisor - receptor existe un sistema de codificación y descodificación único.

- Componente interactivo: es además de la influencia sobre el comportamiento de los otros por medio del intercambio de signos, la organización de las acciones conjuntas que favorece la realización de actividades grupales, comunes para todos los miembros. Se logra si existen determinadas relaciones entre los participantes.

- Componente perceptivo: incluye la percepción interpersonal como variante de la percepción del hombre por el hombre. Si un individuo entra en contacto con otro, es percibido, por este otro, siempre, como personalidad. Las impresiones tienen su papel regulador en la comunicación, pues el conocimiento paulatino del otro conforma el mismo sujeto cognoscente y la certeza de la imagen del otro depende de la organización de las acciones acordadas con él.

La importancia de la comunicación podemos valorarla fundamental ya que por medio de ella se pueden ver al cosas el punto de vista de la otra persona y aceptarlo aunque no pienses igual, entender al otro. Es una especie de percepción y de comprensión del comportamiento del otro que conduce a una sensibilidad por sus necesidades y a una flexibilidad para saberlas manejar con justicia y objetividad. Significa comprender al otro, aunque no se esté de acuerdo con él o no se acepten totalmente sus puntos de vista. Es un poco el secreto de la comunicación. La comprensión del otro conduce a establecer dos principios básicos de la comunicación efectiva. Por otra parte ayuda a mejorar la organización de los flujos y canales lo que permite llevar a cabo el análisis, diagnóstico, planificación y control, destinados a la concreción de resultados, a través de la toma de 
decisiones, la delegación y motivación, para lograr el alcance de los objetivos tanto social como empresarial e individual.Ejerce una mediación cultural y social a todos los niveles y por ultimo ayuda a conservar los valores a promoverlos así como las tradiciones y culturas sociales. ${ }^{6}$

\section{La comunicación en el proceso educativo.}

La comunicación y la educación son una misma cosa, es decir, no puede existir una sin la otra, pues para él el proceso docente educativo es un proceso comunicativo donde el profesor y el alumno participan activamente en la solución de las tareas y en la adquisición de nuevos conocimientos. Por tanto, aprenden unos de otros durante el proceso. Esto nos indica que a través de la comunicación se va a producir un encuentro entre los sujetos, encuentro que va a trascender en un nuevo saber, en una acción transformadora. ${ }^{7}$

Así podemos decir que a través de la comunicación, la educación logra promover la formación integral, armónica y permanente del hombre con orientación humanista, democrática, racional, crítica y creadora, abierta a todas las corrientes del pensamiento universal. ${ }^{7}$

La calidad y excelencia docente universitaria son reconsideradas constantemente a través de diferentes indicadores. Healey ${ }^{8}$ afirmó que la excelencia académica implica un alto nivel de competencias que tiene entre sus objetivos motivar a los estudiantes atendiendo a la diversidad, la comunicación y la reflexión en el proceso de enseñanza - aprendizaje

Glassick y col. ${ }^{9}$ afirmaron que la excelencia docente se caracteriza por una definición clara de los objetivos, una adecuada preparación, el uso de los métodos apropiados, la obtención de resultados significativos, la visibilidad de la enseñanza, la interacción comunicativa y la reflexión crítica. 
La escucha es un elemento primordial, en el contexto universitario algunas veces se da la impresión de que no se dispone de tiempo para escuchar. Se piensa en los problemas propios y no en cómo responder a la persona que nos habla. Se precipita una opinión en cuanto alguien termina de hablar, e incluso se interrumpe antes de que haya concluido.

Según Codina ${ }^{10}$ escuchar es una de las habilidades más difíciles de desarrollar porque requiere ponerse en el lugar de los demás dejando a un lado, aunque sea temporalmente, los paradigmas propios asumiendo que otros pueden ver, sentir y comprenderla realidad de manera diferente

Garcia R ${ }^{11}$ realizo un estudio durante el curso académico 2010/2011 en la universidad Canadá con el objetivo de analizar la influencia de los indicadores de excelencia docente sobre la dimensión de la capacidad comunicativa, obteniéndose como resultado la existencia de vinculación entre la dimensión de la "capacidad comunicativa" con las dimensiones de "desarrollo de la enseñanza", "percepción de necesidades formativas de los estudiantes" y "conocimiento del contexto" a través del análisis de regresión jerárquica.

El estudio demuestro la necesidad de promocionar la interacción comunicativa y las relaciones interpersonales entre docentes y estudiantes a fin de mejorar la excelencia visible en el Educación Superior. ${ }^{11}$

\section{La tecnología de la información y la comunicación en la educación superior.}

La palabra tecnología etiológicamente está conformada por las voces griegas techne que tiene un significado de arte o destreza, y logros con una aceptación relativa al orden del cosmo, al conocimiento.$^{13}$ Según Baelo $\mathrm{A}^{12}$, resume que la tecnología sería un elemento de paso , un 
engranaje que nos permite utilizar la ciencia y los conocimiento científico, para mejorar los proceso y las prácticascotidianas.

Tradicionalmente las universidades se han conformado como un lucus de concentración emergente del poder intelectual de cada época, un poder que se ponía al servicio de la sociedad o de las autoridades establecidas en cada momento.

Al referirnos a la misión y visión de las universidades en la actualidad, las mismas tienen como punto focales en la creación y difusión del conocimiento, a pesar de que sigue teniendo el sentido corporativo la universalidad y la autonomía.

Las TIC en las universidades cobran un importante protagonismo conformándose como elementos esenciales para el desarrollo de la flexibilidad organizativa de las enseñanzas y el desarrollo de nuevas sinergias que inserten plenamente a la universidad en la actual armazón de las sociedades del conocimiento.

La introducción de las TIC en la enseñanza superior (proceso de enseñanza y aprendizaje) ha supuesto una transformación institucional orientada a dar respuesta a las necesidades demandadas por las sociedades del conocimiento. Asi mismo las nuevas exigencias de la educación superior se centran en la mejora del proceso educativo y en este sentido las TIC facilita aspectos relacionados con la mejora del trabajo individual, la autonomía del alumnado, la facilidad para el desarrollo de trabajo en equipo y colaborativos también da la posibilidad de modificar y adaptar los métodos de evaluación y al interacción entre el profesorado y el estudiante. ${ }^{13}$

Podemos decir que en la actualidad no se está explotando en su totalidad a pesar que juega un papel protagónico en la educación a este nivel. 


\section{Resultados de investigaciones acerca del uso de las TIC en la educación superior}

El consejo de universidades de España se ponía de manifiesto como en la practica la totalidad de las universidades española se habían iniciado en las TIC, no obstante el informe señalaba que aún existía dependencia de los métodos didácticos tradicionales para el desarrollo de la docencia.$^{13}$.

López de la de Madrid $\mathrm{C}^{14}$ en su investigación demostró que si existe una relación directivamente proporcional entre al frecuencia y el dominio en el uso de las TIC por parte de los docentes y que no existe una diferencia significativa entre la intensidad de uso en las actividades con la investigación en proporción a la docencia y extensión.

De igual forma Marín, Freddy ${ }^{15}$ en su estudio concluyo que las instituciones de educación superior de Barranquilla requieren estrategias de integración y articulación de tecnologías innovadoras que fortalezcan la didáctica en sus procesos de enseñanza.

Grupo de Investigación en Automatización y Telemática Facultad de Ingeniería Industrial, Universidad de Guayaquil . Ecuador, realizaron una investigación al caula arrojo una idea de cómo el Internet de las Cosas está reformando, y transformando la educación superior de forma autónoma y unificada. ${ }^{16}$

Podemos decir que la implantación de las nuevas tecnologías en el mundo educativo abre un horizonte de posibilidades y recursos que pueden y deben enriquecer los procesos de enseñanza y de aprendizaje. 
Maria L. Parrales-Poveda; Diego R. Sornoza-Parrales; Rocio J. Cano-Andrade; Mercy K. Moreira-Cañarte

\section{Bibliografía.}

[1] Arranguer Díaz F . La educación Superior y las transformaciones de la comunicación. Nómadas (Col) , 5. 1996. Universidad Central. Bogota Colombia .

[2] Las TIC y la educación superior del siglo XXI. 2015 [citado 2018 Jun 05] Disponible en :https://lasticedusupsigloxxi.wordpress.com/el-sistema-de-educacion-superior/

[3] Preparación que brinda la educación superior. 2012 [citado 2018 Jun 05 . http://tareasuniversitarias.com/preparacion-que-brinda-la-educacion-superior.html

[4] Roca Morales Fermín, Serrano González Luisa M, Cuba Yordi Olga Lidia. Un modelo interactivo para la comunicación sociopsicológica. RevHumMed . 2005 [citado 2018 Jun 05] ; 5( 2 ): . Disponible en: http://scielo.sld.cu/scielo.php?script=sci_arttext\&pid=S1727$81202005000200005 \& \operatorname{lng}=\mathrm{es}$.

[5] Comunicación. 2018. EcuRed Enciclopedia Colaborativa Cubana [citado 2018 Jun 05].Disponible en : https://www.ecured.cu/Comunicaci\%C3\%B3n

[6] Comunicación 2013 [citado 2018 Jun 4 05].Disponible http://gicela300495.blogspot.com/2013/12/los-componentes-sociopsicologicos-de-la.html.

[7] Alva Olivos M . Importancia de la comunicación en la educación.2005. [citado 2018 Jun 05].Disponible en : http://manuelalvaolivos.obolog.es/importancia-comunicacion-educacion$\underline{60698}$

[8] Healey, M. . Developing the Scholarship of Teaching in Higher Education: A discipline-based approach. Higher Education Research \& Development 2000, 19

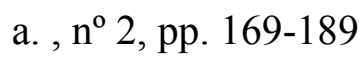

[9] Glassick, C., Taylor, M., Maeroff, G. . La valoración del trabajo académico . México D.F.: ANUIES.2003 
[10] Codina, A. (2004). Saber escuchar. Un intangible Valioso. Intangible Capital. 0, (4,) 1-26.

Disponible en : http://www.intangiblecapital.org/index.php/ic/article/view/23/2

[11] García Ramírez, J.M. . La comunicación, clave de excelencia visible en la Educación Superior. Journal for Educators, Teachers and Trainers , 2012. 3, pp. 25-36

[12] Baelo Álvarez R , Cantón Mayo I . Las tecnologías de la información y la comunicación en la educación superior. 2009. Reviste Iberoamericana de la educación. ISSN 1681-5653. No $50 / 7$.

[13] Consejo de universidad 2003. Plan nacional de evaluación de la calidad de las universidades. Informe Global . Madrid.

[14] López de la de Madrid C . Impacto de las TIC en el docente universitario en el caso de la universidad de Guadalajara . perspectiva educacional 2013. 52(2); p 4-34

[15] Marín, Freddy V, Inciarte, Alicia de J, Hernández, Hugo G, \& Pitre, Remedios C. Estrategias de las Instituciones de Educación Superior para la Integración de las Tecnología de la Información y la Comunicación y de la Innovación en los Procesos de Enseñanza. Un Estudio en el Distrito de Barranquilla, Colombia. Formación universitaria,2017 [citado 2018 Jun 05]; 10(6), 29-38. Disponible en : https://dx.doi.org/10.4067/S0718-50062017000600004

[16] Veintimilla J , Ulloa J , veintimilla M Transformación de la educación superior por medio del surgimiento Del internet de las cosas (iot). 2017. Memorias de la Décima Sexta Conferencia Iberoamericana en Sistemas, Cibernética e Informática. 